\title{
Voltage Controller of a Single Phase Self-Excited Induction Generator
}

\author{
R. Ahshan* and M.T. Iqbal
}

Faculty of Engineering and Applied Science, Memorial University of Newfoundland, St. John's, NL, Canada A1B 3X5.

\begin{abstract}
This paper presents the design of a low cost voltage controller of a single phase Self-Excited Induction Generator (SEIG). The control scheme is based on the measurement of users load voltage and controlling the dump load power using an Analogue Input Power Controller (AIPC). The controller output varies from $2-10 \mathrm{~V}$ and it controls the output AC power going to a resistive dump load. A PI type controller is designed to adjust the dump load as the users load varies to maintain a constant voltage across the load. The system voltage regulation is tested by sudden change in the users load. This paper presents the system description, controller design, and test results.
\end{abstract}

Key Words: Self-excited induction generator, voltage regulation, load control, renewable energy.

\section{INTRODUCTION}

Induction generators are widely used to extract energy from renewable energy resources because they have rugged construction; these generators are simple, reliable, cost effective, and require little maintenance [1-4]. It also has the self protection feature against overload [5], and does not require a DC exciter like synchronous generator [2]. However, poor voltage regulation is a great disadvantage of self-excited induction generators. Therefore, a control system is required to regulate the voltage to meet the constant voltage demand.

This issue has been addressed by several researchers. A DSP based voltage regulator is presented by Dheeraj and Singh [5], where the amount of power required dumping in the dump load is decided by the controller. Self regulation using series capacitor or short-shunt and long-shunt connections have been reported in literature [6-11]. Murthy et al. [7] also proposed a saturable core reactor, and a constant voltage transformer based voltage regulation scheme. The performance of a series capacitor based voltage regulation scheme is not satisfactory because of a limited percentage of voltage regulation. The saturable core reactor based scheme introduces harmonic in the terminal voltage at no load, which vanishes as the load is applied. The constant voltage transformer based voltage regulation scheme provides better result than series capacitor and saturable core reactor based schemes, however, a constant voltage transformer is costly. Optimized utilization of single phase SEIG, system performance, and its transient analysis have been reported by Murthy and Bhim Singh [12,13]. Ojo et al. [14] have presented an inverter assisted single phase induction generator for voltage and frequency control. Bhim Singh [15] has presented the design and implementation of an analog based electronic

*Address correspondence to this author at the Faculty of Engineering and Applied Science, Memorial University of Newfoundland, St. John's, NL, Canada A1B 3X5, Canada; E-mail: rahshan@mun.ca load controller to regulate voltage and frequency of SEIG for constant power applications. Bhim Singh and Gaurav [16] also proposed a voltage frequency controller using an IGBT based current controlled voltage source inverter and a high frequency DC chopper at its DC bus. A pulse width modulated voltage source inverter based voltage controller of an induction generator for stand-alone application is also presented by Jayaramaiah and Fernandes [17]. The control system proposed by Bhim Singh and Jayaramaiah $[16,17]$ requires high cost power electronics, which is a major issue for small scale power generation systems. A rectifier chopper feeding a fixed resistive dump load is discussed by Ammasaigounden [18], where dump power is controlled by varying the duty cycle of the chopper. As choppers receive power from a fixed voltage DC source using a rectifier, this arrangement can not be recommended for AC primary load. Ahmed et al. [19] proposed a static VAR compensator, which consists of thyristor switched shunt capacitor and saturable core reactor which has already been approached by Murthy [7]. The approach by Ahmed et al. [19] differs from the approach by Murthy [7] in terms of a switched capacitor and reactor instead of a fixed value of them.

Our proposed control scheme is based on an analogue input power controller which is the only power electronic module used in the system. A simple operational amplifier based proportional-integral controller is designed to control the input voltage of the analogue input power controller. The control system determines the power to be dumped in the dump load according to the user load variations, and maintains the constant voltage at the users load terminal. The proposed control scheme is very cost effective and simple which is important for a micro power generation unit. The control scheme can be used in micro-hydro and small fixed speed wind turbine in stand-alone applications.

\section{SYSTEM DESCRIPTION}

The proposed system shown in Fig. (1) consists of a prime mover and a two winding single phase induction generator with self-excitation capacitors. User load is connected 


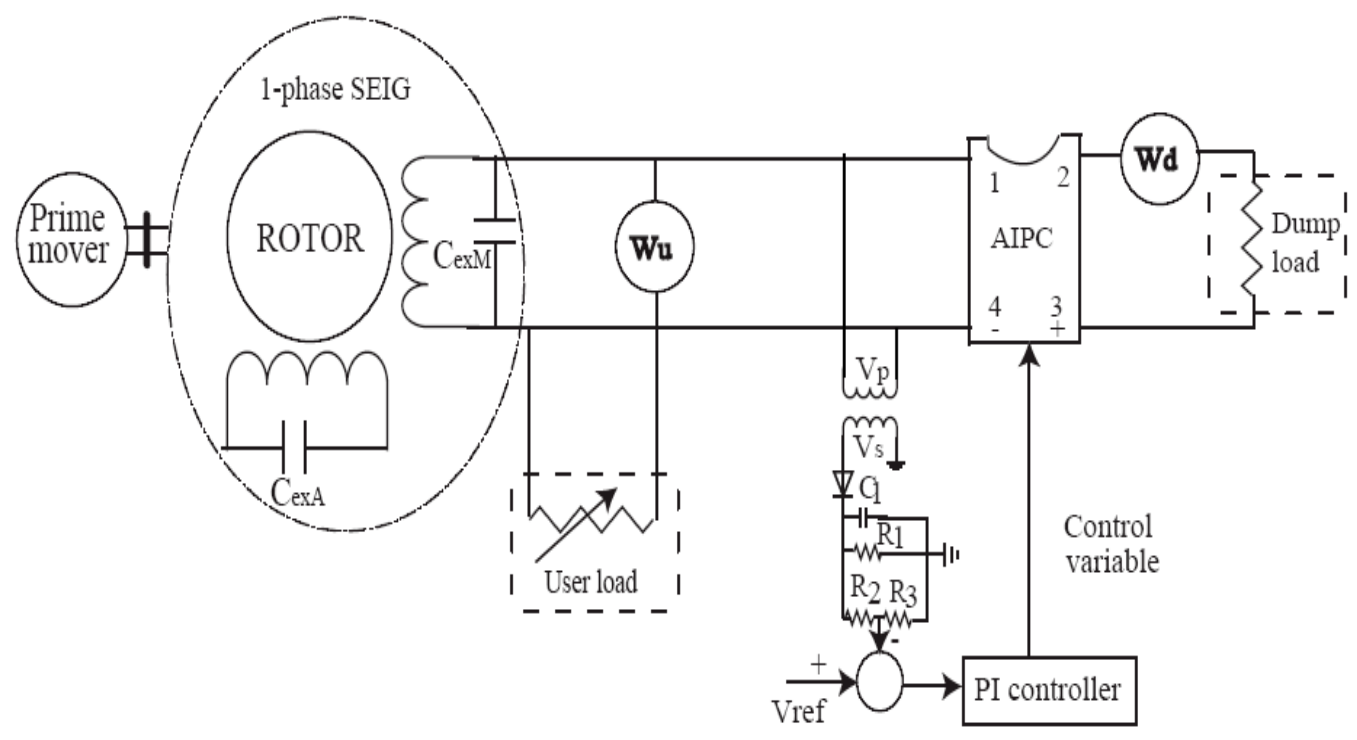

Fig. (1). Block diagram of the proposed system.

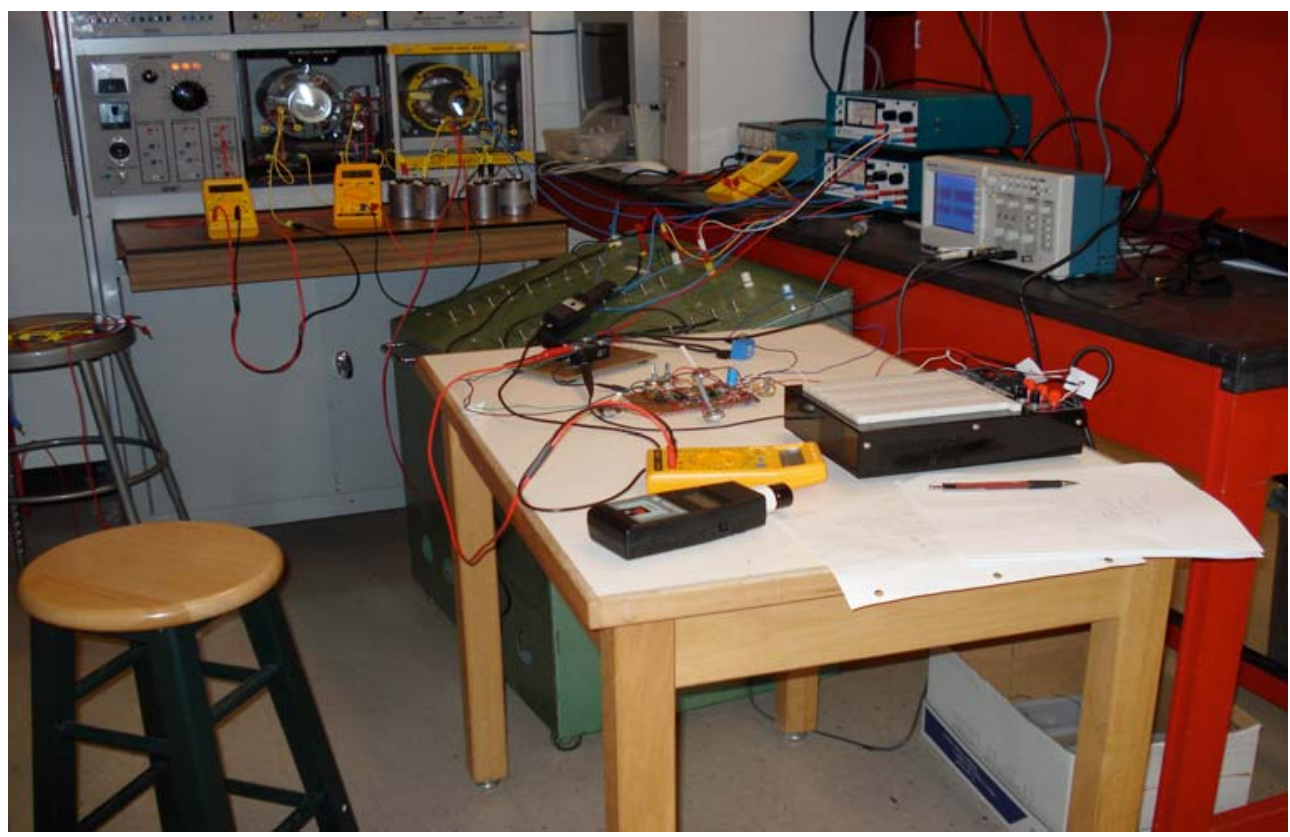

Fig. (2). A photo of the experimental setup.

directly to the main winding of the generator and dump load is connected through AIPC. Two watt meters are used to measure user load and dump load. A $120 \mathrm{~V}, 2.8 \mathrm{~A}, 175 \mathrm{~W}$, $1800 \mathrm{rpm}$ shunt type DC motor is used as a prime mover, which is coupled with the rotor of the induction generator. The prime mover can be replaced by a renewable energy converter such as a micro-hydro or a small wind turbine. A $0.25 \mathrm{HP}, 120 \mathrm{~V}, 60 \mathrm{~Hz}, 1715 \mathrm{rpm}$ single phase induction motor is used as a single phase induction generator using selfexcitation capacitors. The excitation capacitors are connected both across the main and auxiliary winding. The excitation capacitors at the main winding $\mathrm{C}_{\mathrm{exM}}$, and auxiliary winding $\mathrm{C}_{\text {exA }}$, are selected to provide the generator rated terminal voltage at no load condition. In this case, the selected capacitors are at the main winding, $\mathrm{C}_{\mathrm{exM}}=100 \mathrm{uF}, 370 \mathrm{~V} \mathrm{AC}$, and at the auxiliary winding, $\mathrm{C}_{\mathrm{exA}}=100 \mathrm{uF}, 370 \mathrm{~V}$ AC.
The user and the dump loads are considered as the multiple switched resistive loads. The watt meters $\mathrm{W}_{\mathrm{u}}$ and $\mathrm{W}_{\mathrm{d}}$ are used to observe the power flow through the user load and the dump load, respectively. The control scheme of the system consists of a voltage sensor, a peak detector circuit, operational amplifier based proportional-integral controller, and an analogue input power controller. A photo of the experimental setup is shown in Fig. (2).

\section{CONTROL SYSTEM DESIGN AND IMPLEMENTA- TION}

The AIPC is a four terminal device (10PCV25) which has a self-contained power control module integrating with a phase fired logic control system and a solid state relay. The AIPC takes $2-10 \mathrm{~V}$ DC input, and provides variable output, which is rated at $120 / 240 \mathrm{~V} \mathrm{AC,} 25 \mathrm{~A}$. The operating charac- 


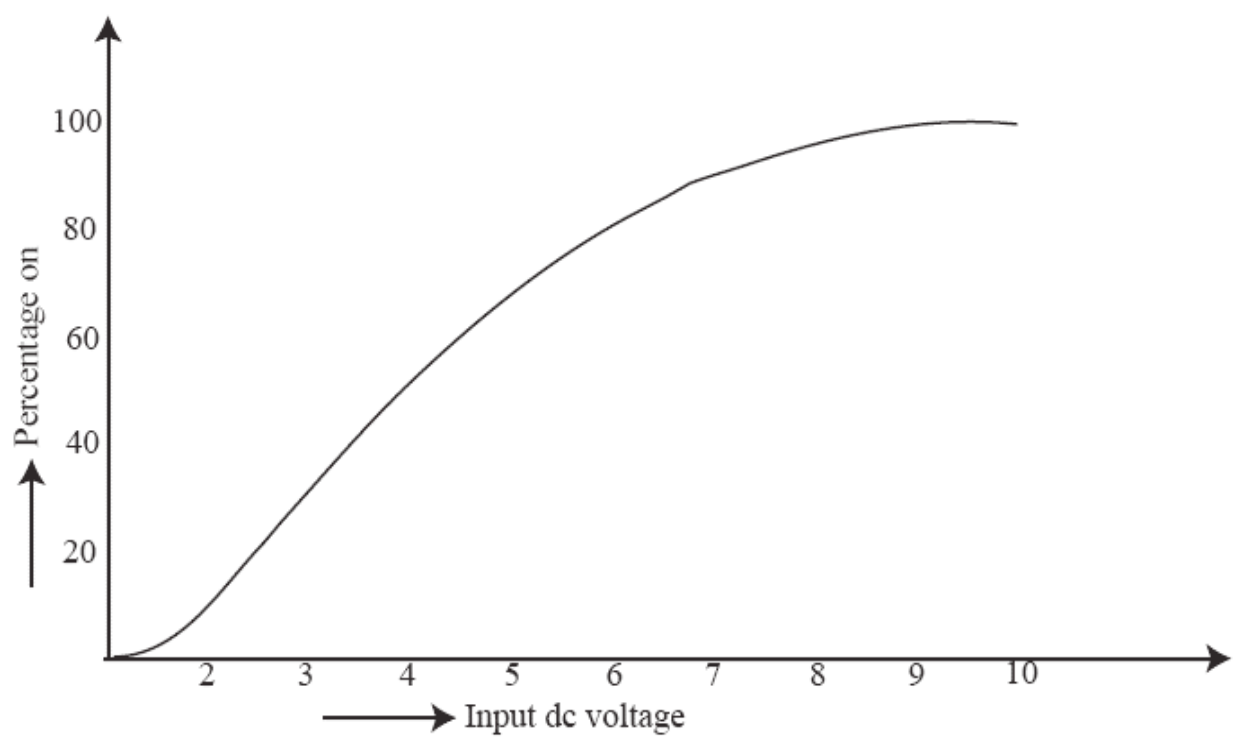

Fig. (3). Operating characteristic of the AIPC.

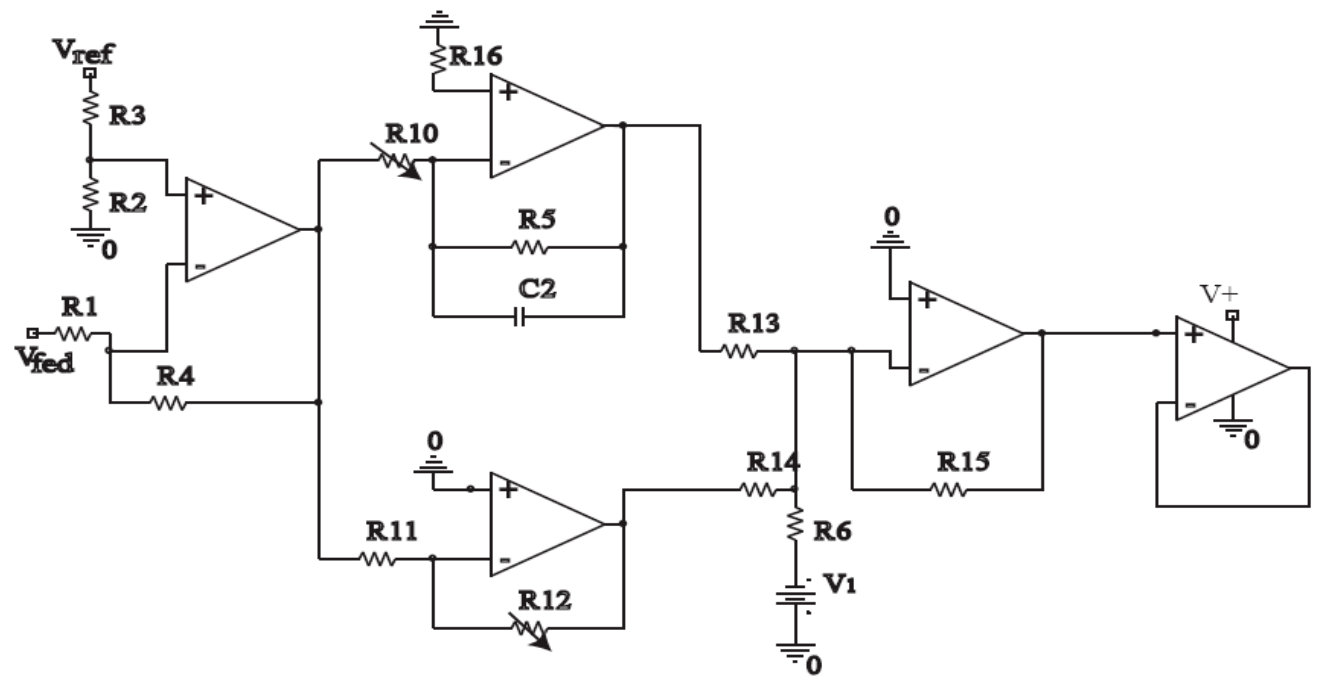

Fig. (4). Operational amplifier based PI controller.

teristic of the AIPC is shown in Fig. (3). It shows that the percentage on-time of the AIPC depends on the input DC voltage; that means the output of the AIPC is controllable and the control variable is input voltage which varies from 2 $10 \mathrm{~V}$. Therefore, the objective of the PI regulator is to control the AIPC output according to the terminal voltage by controlling the analogue input voltage of the AIPC. In other words, the dump power is controlled by controlling the output of the AIPC. The control system is designed to vary the percentage on-time in case of user load increase or decrease to maintain the voltage constant at the user load terminal. The system non-linearity and the non-linear operating characteristic of the AIPC limit the controller performance within a certain range.

A voltage transformer is used to obtain the user load terminal voltage under various load conditions. The voltage output of the secondary terminal is passed through a voltage averaging circuit to obtain a DC value, which is used as the feedback signal for the PI regulator. The feedback voltage is compared with a reference signal, which generates an error signal. A simple operational amplifier based PI controller is shown in Fig. (4). The best controller parameter value for the proposed scheme was found to be $\mathrm{K}_{\mathrm{p}}=1.475$ and $\mathrm{K}_{\mathrm{i}}=$ 0.0718. A single supply voltage follower is used at the controller output to obtain only positive control voltage for the AIPC.

\section{TEST RESULTS}

The voltage controller test results of a single phase SEIG are shown in the Figs. (5-10) in terms of the voltage and current response both at the user and the dump load terminal. Figs. (5-7) show the dump load terminal voltage and current at different user loads. The user load variation is shown in Fig. (8). The voltage and current at the user load terminal under user load variations are shown in Figs. (9 and 10). The 


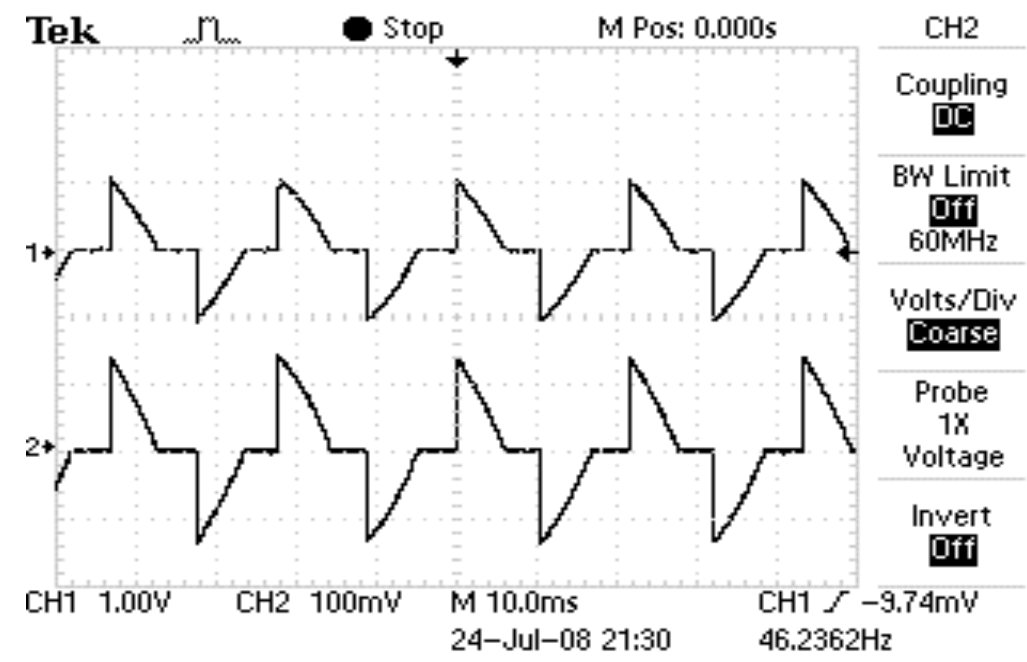

Fig. (5). Voltage and current at the dump load terminal when user load at $70 \mathrm{ohm}$.

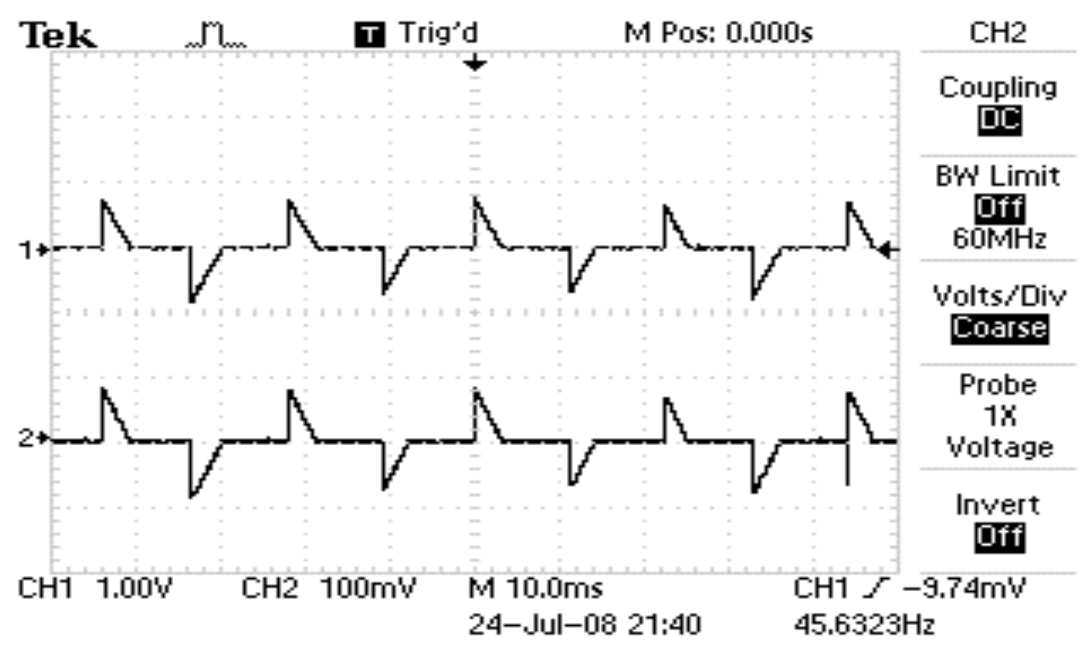

Fig. (6). Voltage and current at the dump load terminal when user load at $46 \mathrm{ohm}$.

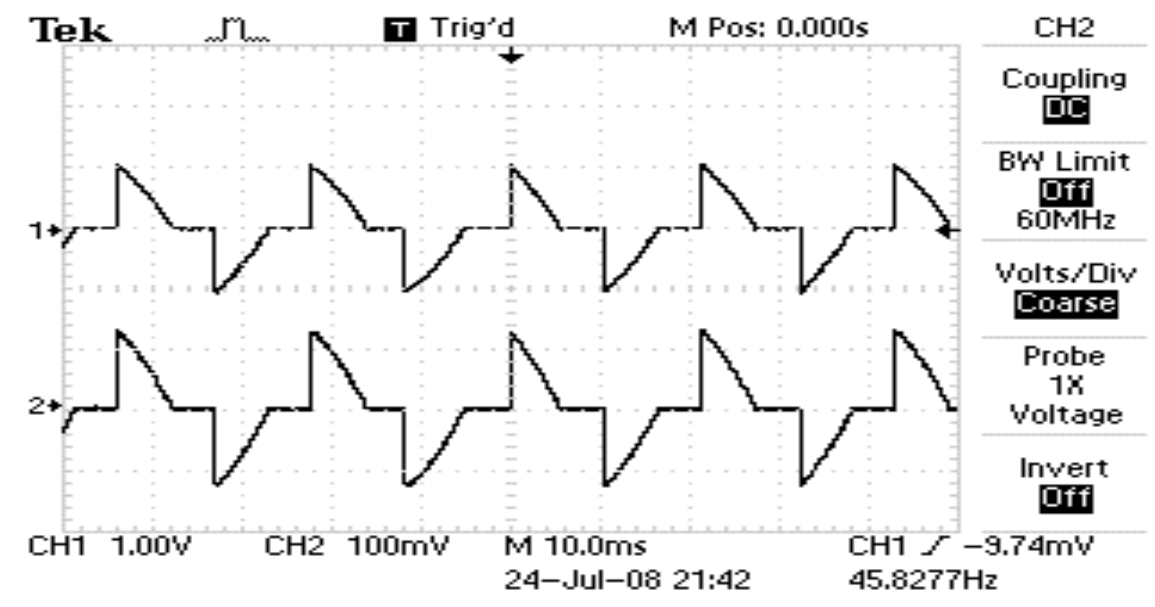

Fig. (7). Voltage and current at the dump load terminal when user load back at $70 \mathrm{ohm}$.

upper and lower traces of Figs. (5-10) represent the voltage and the current, respectively. The voltages are measured us- ing a $100 \mathrm{X}$ probe, and the currents are measured using a current probe, which was set at $100 \mathrm{mV} / \mathrm{A}$. 


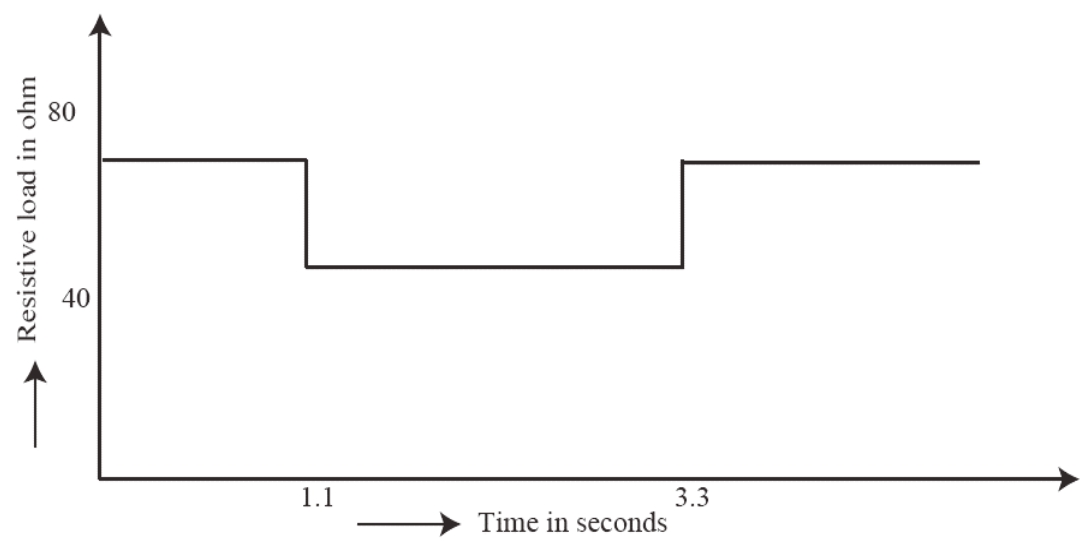

Fig. (8). User load variations.

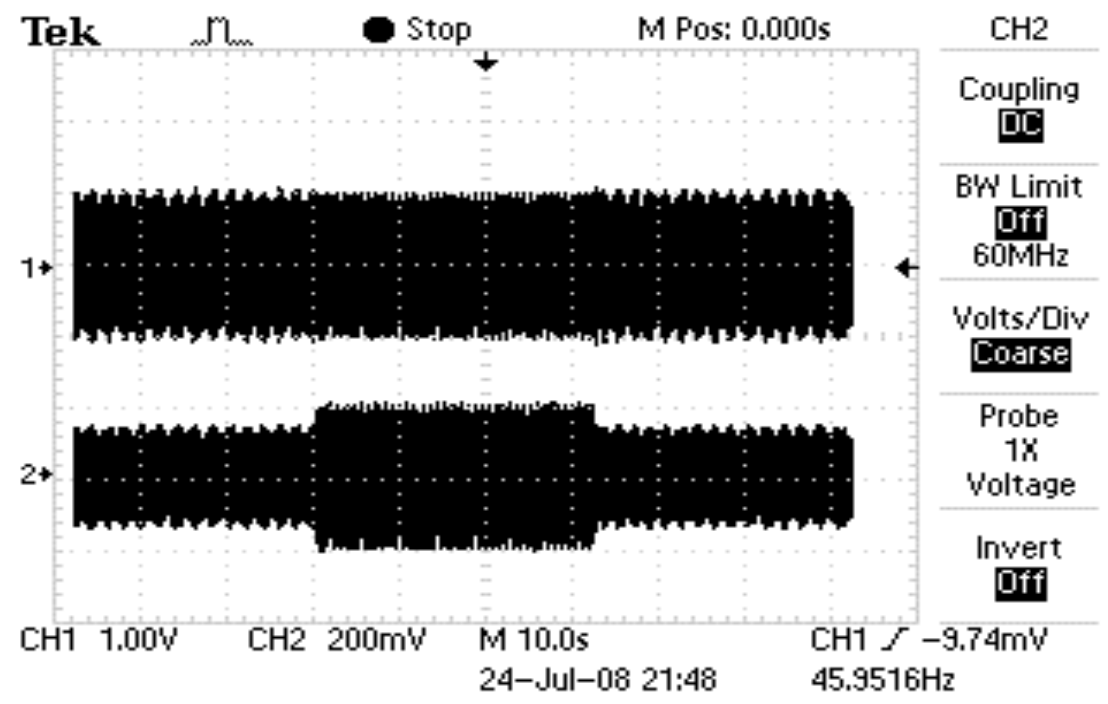

Fig. (9). Voltage and current at the user load terminal under a load disturbance.

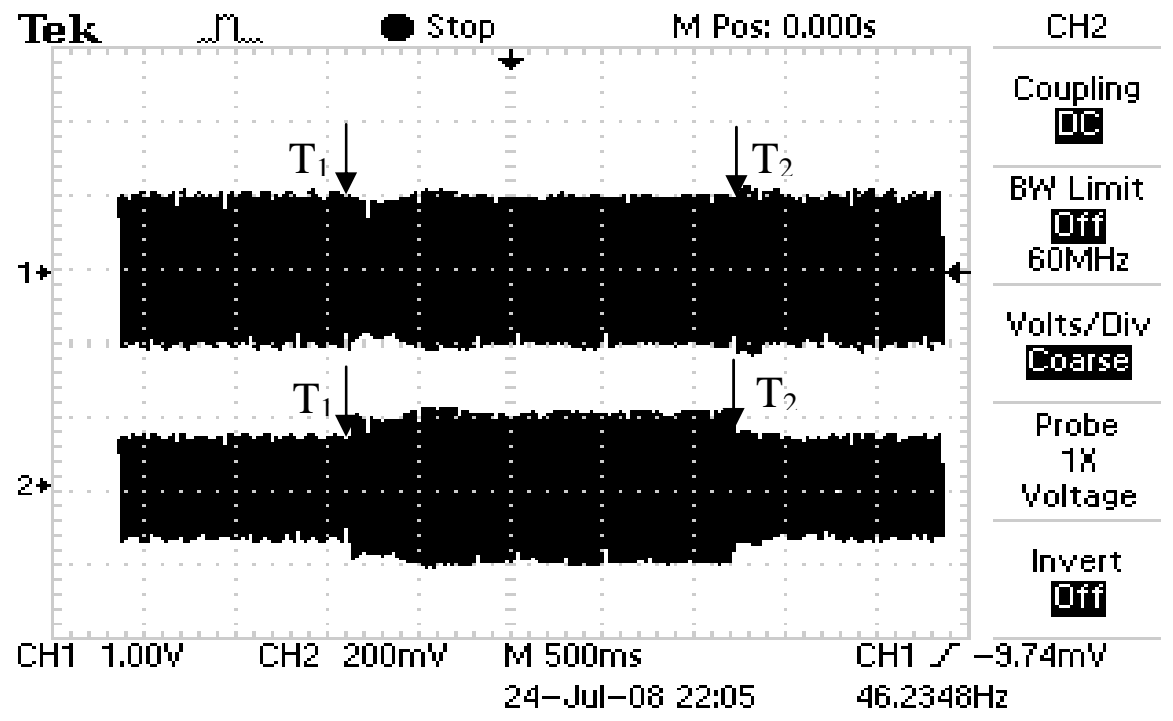

Fig. (10). Voltage and current at the user load terminal under load disturbance at $T_{1}$ and $T_{2}$.

Fig. (5) shows the voltage and the current at the dump load terminal when the user load is at $70 \mathrm{ohm}$. When the user load is increased by changing resistance from $70 \mathrm{ohm}$ to 46 ohm as shown in Fig. (8), the voltage and the current at the 
dump load terminal are reduced, which is shown in Fig. (6). The current going to the dump load is reduced by the controller to allow more current flow to the user load as the output power of the generator is required to be constant for a constant mechanical input. When the user load is again reduced by increasing the resistance to $70 \mathrm{ohm}$, the voltage and the current at the dump load terminal reach their previous value which means the dump power is increased as user load demand is reduced.

Figs. (9) and (10) show the user load terminal voltage and current response while the change in the user load was 34 percent. Fig. (9) shows the result for longer time period, whereas Fig. (10) shows the result for only 4.5 seconds, and shows the transient in voltage and current during the user load change. Until time $T_{1}$ the user load is $70 \mathrm{ohm}$. At $T_{1}$ the load is increased, which causes the increase in user load current. The voltage at $T_{1}$ decreases briefly, due to increase in the user load; however, the voltage becomes its previous value within 0.3 seconds, due to a proper control action. The voltage and the current remain unchanged until the next change in the user load. Fig. (10) also shows the voltage and the current transient, due to the next change in the user load at $T_{2}$. At $T_{2}$, the user load is again reduced to value as it was before time $T_{1}$. As a consequence, the voltage at $T_{2}$ first increases briefly but it comes back to its previous value within 0.25 seconds.

\section{CONCLUSIONS}

A simple cost effective power electronics based load controller is developed and tested for a single phase self-excited induction generator. The designed controller performs as a voltage regulator for the SEIG. A 34 percent change in the user load results an 11.8 percent voltage change in the test system while there was no control action. However, with the proposed control scheme, test results show that the load voltage change is negligible, due to the same percentage change in the user load. The designed controller achieves the required voltage with a transient time of less than 0.5 seconds. The proposed voltage controller can be used in micro-hydro and other renewable energy installations.

\section{NOMENCLATURE}

$\begin{array}{lll}\mathrm{AIPC} & = & \text { Analogue input power controller } \\ \mathrm{AC} & = & \text { Alternating current } \\ \mathrm{C}_{\mathrm{exM}} & = & \text { Main winding excitation capacitor } \\ \mathrm{C}_{\mathrm{exA}} & = & \text { Auxiliary winding excitation capacitor } \\ \mathrm{DSP} & = & \text { Digital signal processing } \\ \mathrm{DC} & = & \text { Direct current } \\ \mathrm{HP} & = & \text { Horse power } \\ \mathrm{IGBT} & = & \text { Insulated gate bi-polar transistor } \\ \mathrm{SEIG} & = & \text { Self-excited induction generator } \\ \mathrm{T}_{1} & = & \text { Time at which user load is increased } \\ \mathrm{T}_{2} & = & \text { Time at which user load is decreased } \\ \mathrm{V}_{\mathrm{p}} & = & \text { Primary voltage of the voltage sensor }\end{array}$

$\begin{array}{lll}\mathrm{V}_{\text {ref }} & = & \text { Reference voltage for the controller } \\ \mathrm{V}_{\mathrm{s}} & = & \text { Secondary voltage of the voltage sensor } \\ \mathrm{W}_{\mathrm{u}} & = & \text { User load power observation meter } \\ \mathrm{W}_{\mathrm{d}} & = & \text { Dump load power observation meter }\end{array}$

\section{REFERENCES}

[1] Singh, S.P.; Jain M.P.; Bhim Singh, A. New technique for analysis of self-excited induction generator. Electric Mach. Power Syst., 1995, 23, 647-656.

[2] Ermis, M.; Ertan H.B.; Demirekler, M.; Saribatir, B.M.; Uctug Y.; Sezer, M.E.; Cadirci, I. Various induction generator schemes for wind-electricity generation. Electric. Power Syst. Res., 1992, 23, 71-83.

[3] Shridhar, L.; Singh, B.P.; Jha, C.S. A step towards improvements in the characteristics of self-excited induction generator. IEEE Trans. Energy Convers., 1993, 8 (1), 40-46.

[4] Orabi, M.; Youssef, M.Z.; Jain, P.K. Investigation of Self-excited Induction Generators for Wind Turbine Applications. Proceedings of the Canadian Conference on Electrical and Computer Engineering, Niagara Falls, Canada, May 2004, vol. 4, pp. 1853-1856.

[5] Dheeraj, K.P.; Singh, S.P. DSP based induction generator controller for single phase self- excited induction generator. Int. J. Emerg. Electric. Power Syst., 2008, 9 (1), 1-9.

[6] Murthy, S.S. A novel self-excited self-regulated single phase induction generator Part 1: basic system and theory. IEEE Trans. Energy Convers., 1993, 8 (3), 377-382.

[7] Murthy, S.S.; Rai, H.C.; Tandon, A.K. A novel self-excited selfregulated single-phase induction generator Part I1: Experimental investigation. IEEE Trans. Energy Convers., 1993, 8 (3), 383-388.

[8] Rahim, Y.H.A.; Alolah, A.; Al-Mudaiheem, R.I. Performance of single phase induction generator. IEEE Trans. Energy Convers., 1993, 8 (3), 389-395.

[9] Ojo, O. The transient and qualitative performance of a self excited single phase induction generator. IEEE Trans. Energy Convers., 1995, 10 (3), 493-501.

[10] Ojo O. Performance of self excited, single phase induction generators with shunt, short-shunt and long shunt excitation connections. IEEE Trans. Energy Convers., 1996, 11 (3), 477-482,

[11] Murthy, S.S.; Rai, H.C.; Bhim, S.; Singh, B.P.; Goyal, N.K.; Vaishya, M.O. New Experimental Finding on a Novel Two Winding Single Phase Self Excited Induction Generator for Standby Power Generation. Proceedings of the International Conference on Power Electronics, Drives and Energy Systems for Industrial Growth, New Delhi, India, January, 1996, vol. 2, pp. 674-678.

[12] Bhim Singh. Optimum utilization of single phase induction machine as a capacitor self excited induction generator. Electric. Mach. Power Syst., 1987, 13 (2), 73-85.

[13] Salama, M.H.; Holmes, P.G. Transient and steady state load performance of a stand alone self excited induction generator. IEE Proc. Electric Power Appl., 1996, 143, 50-58.

[14] Ojo, O.; Omozusi, O.; Jimoh, A.A. The operation of an inverter assisted single phase induction generator. IEEE Trans. Indian. Electron., 2000, 47 (3), 632-640.

[15] Bhim Singh; Murthy S.S.; Shushma G. An electronic Voltage And Frequency Controller For Single Phase Self-Excited Induction Generators For Pico-Hydro Applications. Proceedings of the International Conference on Power Electronics, Drives and Energy Systems for Industrial Growth, 2005, vol. 1, pp. 240-245.

[16] Bhim Singh; Kasal, G.K. Voltage and Frequency Controller for Isolated Asynchronous Generators Feeding 3-phase 4-Wire Loads. IEEE International Conference on Industrial Technology, December 2006, pp. 2773-2778.

[17] Jayaramaiah, G.V.; Fernandes, B.G. Novel Voltage Controller for Stand-alone Induction Generator using PWM-VSI. IEEE Industry Application Conference, October 2006, vol. 1, pp. 204-208.

[18] Ammasaigounden N.; Subbiah, M. Chopper-controlled wind-driven self-excited induction generators. IEEE Trans Aerosp Electron. Syst., 1989, 25 (2), 268-276. 
[19] Ahmed, T.; Ogura, K.; Soshin, K.; Hiraki, E.; Nakaoka, M. SmallScale Wind Turbine Coupled Single Phase Self-Excited Induction Generator with svc for Isolated Renewable Energy Utilization.
Proceedings of the $5^{\text {th }}$ International Conference on Power Electronics and Drive System, November 2003, vol. 1, pp. 781-786.

Received: January 15, 2009

Revised: April 13, 2009

Accepted: April 13,2009

(C) Ahshan and Iqbal; Licensee Bentham Open.

This is an open access article licensed under the terms of the Creative Commons Attribution Non-Commercial License (http://creativecommons.org/licenses/by-nc/3.0/) which permits unrestricted, non-commercial use, distribution and reproduction in any medium, provided the work is properly cited. 